\title{
Morphological and Rheological Characterization of Gold Nanoparticles Synthesized Using Pluronic P103 as Soft Template
}

\author{
Nancy Tepale, ${ }^{1}$ Victor V. A. Fernández-Escamilla,, ${ }^{2}$ Carlos Álvarez, ${ }^{1}$ Eric Flores-Aquino, ${ }^{3}$ \\ Valeria J. González-Coronel, ${ }^{1}$ Daniel Cruz, ${ }^{1}$ and Manuel Sánchez-Cantú ${ }^{1}$ \\ ${ }^{1}$ Facultad de Ingeniería Química, Benemérita Universidad Autónoma de Puebla, Avenida San Claudio y 18 Sur, \\ 72570 Puebla, PUE, Mexico \\ ${ }^{2}$ Departamento de Ciencias Tecnológicas, Universidad de Guadalajara, Avenida Universidad No. 1115, 47820 Ocotlán, JAL, Mexico \\ ${ }^{3}$ Laboratorio de Nanocatálisis, Centro de Nanociencias y Nanotecnología, Universidad Nacional Autónoma de México, \\ Km. 107 Carretera Tijuana-Ensenada, 22860 Ensenada, BC, Mexico
}

Correspondence should be addressed to Nancy Tepale; ntepale@hotmail.com

Received 12 November 2015; Accepted 11 January 2016

Academic Editor: Antonios Kelarakis

Copyright (C) 2016 Nancy Tepale et al. This is an open access article distributed under the Creative Commons Attribution License, which permits unrestricted use, distribution, and reproduction in any medium, provided the original work is properly cited.

\begin{abstract}
The synthesis of gold nanoparticles (Au-NPs), using Pluronic ${ }^{\circledR}$ P103 as soft template to design tuned hybrid gold/P103 nanomaterials, is reported here. The effect of the concentration of P103 and the synthesis temperature on the growth, size, and morphology of Au-NPs were studied. The rheological properties of these hybrid nanomaterials at different measured temperatures were studied as well. By increasing the concentration of P103, the micelles progressively grew due to an increase in the number of surface cavities. These cavities came together causing large nucleation centers and developing larger Au-NPs. The synthesis temperature was varied to induce significant dehydration of the P103 micelles. Below the cloud point temperature micelles underwent distinct changes related to spherical-to-polymer-like micelles transitions. Two nanostructures were formed: (1) small Au-NPs arranged on the surface of micelles, which acted as soft templates, and (2) large and independent Au-NPs. Above the cloud point temperature, Au-NPs were related to the shape and size of the P103 micellar aggregates. Rheological measurements showed that viscosity was sensitive to the concentration of P103. Also, it was demonstrated that synthesis temperature had a considerable influence on viscosity of the produced nanomaterials.
\end{abstract}

\section{Introduction}

Hybrid nanomaterials fabricated from polymers and inorganic nanoparticles (NPs) have been the subject of extensive investigations due to their distinct advantages, such as improved water solubility, stimuli-responsiveness, excellent biocompatibility, and facile introduction of functional units. Therefore, promising applications in the field of imaging, detection, drug/gene delivery, diagnostics, and nanoreactors are being extensively investigated [1]. Polymer assemblies provide excellent templates or matrices for the spatial organization of inorganic NPs, resulting in hybrid nanomaterials [2]. Sakai and Alexandridis [3] have reported a single-step synthesis of gold nanoparticles (Au-NPs) using poly(ethylene oxide)-poly(propylene oxide)-poly(ethylene oxide) (PEO-PPO-PEO) triblock copolymers, commercially known as Pluronic.

The Pluronic types are capable of forming micelles in aqueous media due to their amphiphilic character [4]. At low Pluronic concentrations, spherical micelles grow progressively to form polymer-like micelles as the temperature is increased. In this sense, the temperature at which micelles are formed is known as the critical micelle temperature (CMT). Heating beyond the CMT drastically reduces the hydration of micelles, resulting in a predominantly separated hydrophobic phase. The temperature where the phase separation occurs is known as the cloud point temperature (CPT) [5-8].

Micelles formed by Pluronic P103 have surface cavities that are in direct contact with the chloroauric acid aqueous solution $\left(\mathrm{HAuCl}_{4(\mathrm{aq})}\right)$; thus they are mainly responsible for 
the reduction of gold ions to form gold nanoparticles [2]. For instance, by varying the copolymer concentration and temperature, the characteristics of Pluronic micellar assemblies can be easily varied $[9,10]$. In consequence, it is possible to tune up the shape and size of the overall morphology of the hybrid nanomaterials [11, 12].

UV-visible studies are the best spectroscopic techniques employed to monitor the synthesis of Au-NPs on the basis of their surface plasmon resonance (SPR). The peak position, maximum absorbance, and band shape of the plasmon resonance band depend on the particle structure, size, geometry, polydispersity, and the surrounding medium $[12,13]$. The surface plasmon property allows the use of Au-NPs for many applications in the bioscience and medical fields [14-17].

Recent advances in colloidal chemistry and their applications in the biomedical field explore several new concepts of target drug delivery systems [18, 19]. Therefore, it is important to extend the characterization techniques due to the new applications of Au-NPs. For example, drug release from semisolid carriers is influenced by the rheological behaviour [20]. The linear and nonlinear rheological behaviors of semidiluted aqueous micellar solutions of P103 have been reported as function of temperature and concentration, where shear viscosity and storage modulus increased three orders of magnitude with increasing temperature. These changes are related to the spherical-to-polymer-like micellar transition where the length of the micelles and the entanglement number density augment with increasing temperature [21]. Materials that change their structure in response to environmental stimuli such as temperature $(T)$ are called "intelligent" or "smart" materials. In this context, for many applications, it is important to understand the rheological properties of complex fluids containing Au-NPs, since rheology has a direct relationship with their microstructure [22].

In this work, the synthesis of Au-NPs using Pluronic P103 as reductant and soft template in order to design tuned hybrid gold/P103 nanomaterials of different sizes and shapes is reported. The effect of P103 concentration and synthesis temperature on kinetics, size, and morphology of gold nanoparticles were studied. In order to study the effect of synthesis temperatures $\left(30^{\circ} \mathrm{C}\right.$ to $\left.50^{\circ} \mathrm{C}\right)$ on the formation of $\mathrm{Au}-\mathrm{NPs}$, a range was selected to induce significant dehydration of the P103 micelles. Additionally, rheological properties of hybrid gold/P103 nanomaterials aqueous solutions were analyzed to explore the effect of the size and shape of Au-NPs on their shear viscosity as function of P103 concentration and measured temperature.

\section{Materials and Methods}

2.1. Materials. Hydrogen tetrachloroaurate (III) hydrate $\left(\mathrm{HAuCl}_{4} \cdot 3 \mathrm{H}_{2} \mathrm{O} ; 99.9 \%\right)$ was purchased from Sigma-Aldrich. Triblock polymer $\mathrm{P} 103\left(\mathrm{PEO}_{17} \mathrm{PPO}_{60} \mathrm{PEO}_{17}\right)$ from BASF was used as received. Double distilled water was used for all preparations.

2.2. Synthesis of $A u-N P$ s. Aqueous $P 103$ solutions were prepared in vials by mixing the copolymer with water under agitation at room temperature for $12 \mathrm{~h}$. Then, the vials were placed in a water bath at the synthesis temperatures (30, $35,40,43,45$, and $50^{\circ} \mathrm{C}$ ) for $12 \mathrm{~h}$ to ensure stabilization of the P103 micelles. To avoid light degradation of samples, vials were covered with aluminum foil. Aqueous solutions (total mass of $20 \mathrm{~g}$ ) of $\mathrm{P} 103(10,15$, and $20 \mathrm{wt} . \%)$ and $\mathrm{HAuCl}_{4}$ $(2.0 \mathrm{mM})$ were placed in screw-capped glass bottles. The mixing ratio of $\mathrm{HAuCl}_{4}$ to $\mathrm{P} 103$ was $1 / 9$, according to Sakai's method [3]. Concentration of $\mathrm{HAuCl}_{4}$ was kept constant at $2.0 \mathrm{mM}$ in all mixtures. Reaction mixtures were kept in a water thermostat bath (Julabo F12) during $5 \mathrm{~h}$ at the synthesis temperature under static conditions. Then, samples were cooled at room temperature and stored in darkness to avoid light degradation.

2.3. Methods. UV-Vis spectroscopy was used to measure the reduction of $\mathrm{HAuCl}_{4}$ and consequently the formation of gold nanoparticles by observing changes in the absorption spectra at $220 \mathrm{~nm}$ and $540 \mathrm{~nm}[2,3]$. Samples were measured with a GENESYS 6 UV-visible spectrometer (Thermo Spectronic).

The size and shape of gold nanoparticles were determined in a JEOL-JEM-2010 Transmission Electron Microscope (TEM) in the conventional transmission mode using an accelerating voltage of $80 \mathrm{kV}$. Samples were prepared by mounting a drop of solution on a carbon-coated $\mathrm{Cu}$ grid and allowing it to air-dry.

Steady simple shear tests were performed in an AR-G2 rotational stress-controlled rheometer (TA Instruments) with a cone-and-plate geometry of $2^{\circ}$ and $60 \mathrm{~mm}$ in diameter. A humidification chamber was set around the geometry to minimize water evaporation from the samples. Temperature was controlled within $\pm 0.1^{\circ} \mathrm{C}$ during measurements using a Peltier plate system. Measurements were carried out at 30, 34, 37 , and $40^{\circ} \mathrm{C}$. All rheological measurements were performed at least three times, reporting the average values. Simple shear rate sweeps were performed under steady state conditions from 1 to $100 \mathrm{~s}^{-1}$. Vials were placed in a water bath at the measured temperature for $12 \mathrm{~h}$ before running the test to ensure stabilization of the sample. For each test, about $2 \mathrm{~mL}$ of sample was carefully transferred to the rheometer plate, minimizing any possible destruction of the sample.

\section{Results and Discussion}

Figure 1 shows typical UV-visible scans of a sample prepared with a P103 aqueous solution at $10 \mathrm{wt} . \%$ and synthesis temperature of $30^{\circ} \mathrm{C}$. Under these conditions P103 formed spherical micelles [9]. It can be noticed that aqueous solution of P103 did not show any absorption band in the visible region. However, as soon as $\mathrm{HAuCl}_{4}$ was added, three prominent peaks appeared at 220,320 , and $540 \mathrm{~nm}$, due to the presence of $\mathrm{AuCl}_{4}^{-}$ions, the ligand to metal charge transfer band (LMCT), and surface plasmon resonance (SPR) of Au-NPs, respectively $[2,3,12,23]$.

Their intensity variation is presented in Figure 2. The $\mathrm{AuCl}_{4}{ }^{-}$ions $(220 \mathrm{~nm}$ peak) produced a maximum intensity with no sign of Au-NPs absorbance $(540 \mathrm{~nm})$. Then a sudden decrease in the intensity of the $220 \mathrm{~nm}$ peak with simultaneous increase in the $540 \mathrm{~nm}$ peak was observed due to the formation of Au-NPs. After 200 minutes, intensity of 


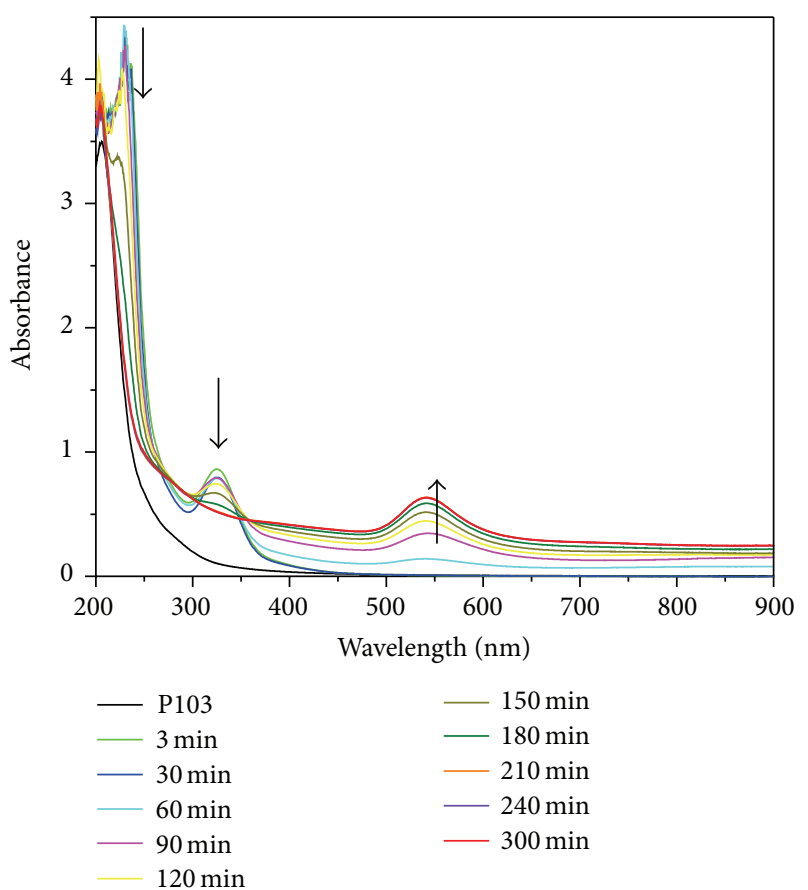

Figure 1: Absorbance versus wavelength of $\mathrm{HAuCl}_{4}(2 \mathrm{mM})$ and P103 (10 wt.\%) aqueous solutions at different measured times and synthesis temperature of $30^{\circ} \mathrm{C}$. Curve referred to as P103 corresponds to the reference solution (without $\mathrm{HAuCl}_{4}$ ).

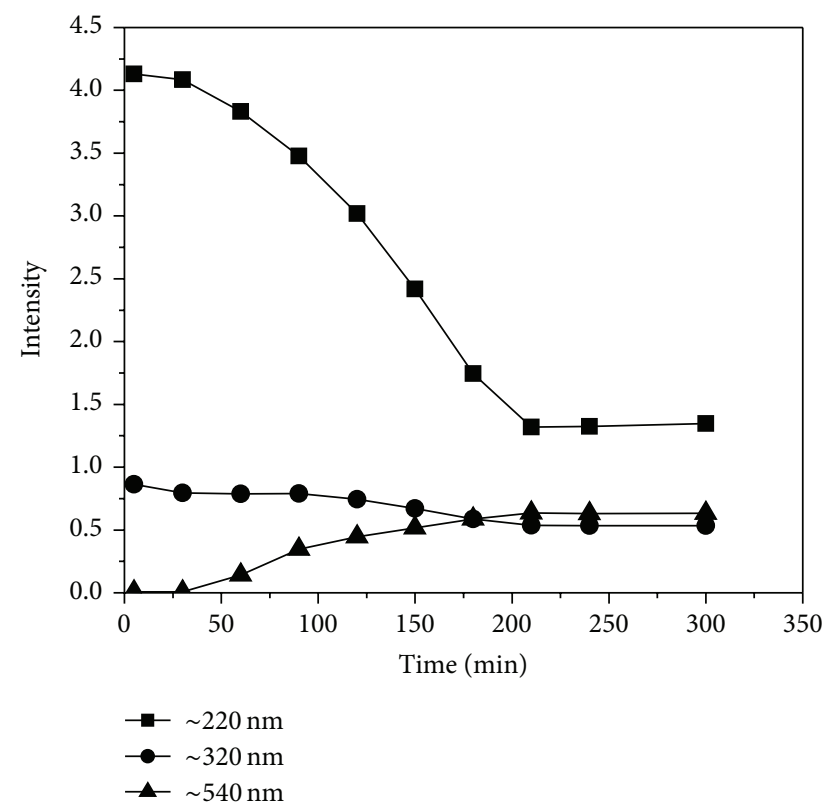

FIGURE 2: Intensity of the UV-Vis absorbance peaks measured at 220, 320 , and $540 \mathrm{~nm}$ for $\mathrm{HAuCl}_{4}(2 \mathrm{mM})$ and $\mathrm{P} 103$ (10 wt.\%) aqueous solutions at $30^{\circ} \mathrm{C}$.

the three peaks remained constant, indicating the end of the reaction.

It has been proved that the P103 copolymer at low concentrations is very efficient forming nanoparticles from $\mathrm{HAuCl}_{4}$ in aqueous solutions in the absence of other reductant and stabilizer agents $[2,3]$. However, synthesis of Au-NPs at the semidiluted aqueous solutions of P103, where a rich variety of micellar structures are formed as a function of temperature and concentration, has not been reported yet [9].

The effect of reaction temperature for various P103 concentrations on the synthesis of gold nanoparticles is shown in Figure 3. Maximum intensity absorbance $\left(I_{\max }\right)$ measured at $540 \mathrm{~nm}$ was plotted versus various reaction temperatures $\left(30,35,40,43,45\right.$, and $\left.50^{\circ} \mathrm{C}\right)$ at different $\mathrm{P} 103$ concentrations $(10,15$, and $20 \mathrm{wt} . \%)$. At $30^{\circ} \mathrm{C}, I_{\max }$ increased with increasing $\mathrm{P} 103$ concentration due to the progressive growth of spherical micelles together with Au-NPs. These micelles increased the number of surface cavities (nucleation centers) that subsequently form Au-NPs.

Moreover, when the polymer concentration increased, it caused not only a large increment in absorbance, but also a slight shift on the absorption band to larger wavelength suggesting that nanoparticles size increased (see inset (a) in Figure 3). The excessive presence of polymer allows surface cavities to come together causing large nucleation centers; this behavior could be responsible for the increase in size of the Au-NPs [2,23]. Therefore, higher concentrations not only facilitate the reduction due to the presence of more surface cavities but will simultaneously entrap all nucleating centers in their micellar phase. However, when independent Au-NPs separate from the micelles, they generate their own SPR $[2,3]$.

By increasing the synthesis temperature to $35^{\circ} \mathrm{C}$, micelles exhibited changes related to the spherical-to-polymer-like micellar transition, where micelles' length and the entanglement number density augmented [21]. Polymer-like micelles have a greater surface area than spherical micelles, which causes an increase of the active sites where the $\mathrm{AuCl}_{4}{ }^{-}$ions are mostly reduced. In consequence, an increment in Au-NPs can be observed as an increase in the UV-Vis spectra absorbance intensity [24]. On inset (b) in Figure 3, a band centered at ca. $548 \mathrm{~nm}$ was observed for $10 \mathrm{wt} . \%$ of P103, indicating the formation of spherical gold nanoparticles. When P103 concentration increased (15 wt.\%), an additional broad band at ca. $740 \mathrm{~nm}$ appeared to have originated from the selfaggregation of independent large colloidal NPs produced by the growing nucleation center [2]. As it was discussed above, the polymer-like micelles increased their aggregation number, which causes these collisions and increase in their surface cavities, which allowed the formation of larger nanoparticles. Consequently, besides spherical particles, large anisotropic aggregates might exist in samples, as it will be further confirmed by TEM images.

It has been reported for P103 that CPT is reached at ca. $40^{\circ} \mathrm{C}$, leading to a reversible phase separation of polymer rich and water rich phases, with increasing size of P103 micellar clusters (polymer aggregates) $[8,9]$. In other words, at certain temperature, water becomes a poor solvent to the polymer, possibly due to the new and less-polar polymer conformation, causing the prevalence of the polymer-polymer interaction and the growth of polymer aggregates, which leads to phase separation [8]. Álvarez-Ramírez et al. [9] reported the temperature-composition phases diagram of P103/water, where P103 samples with concentrations of 10, 15, and $20 \mathrm{wt} . \%$ have a CPT of 39,40 , and $41^{\circ} \mathrm{C}$, respectively. 


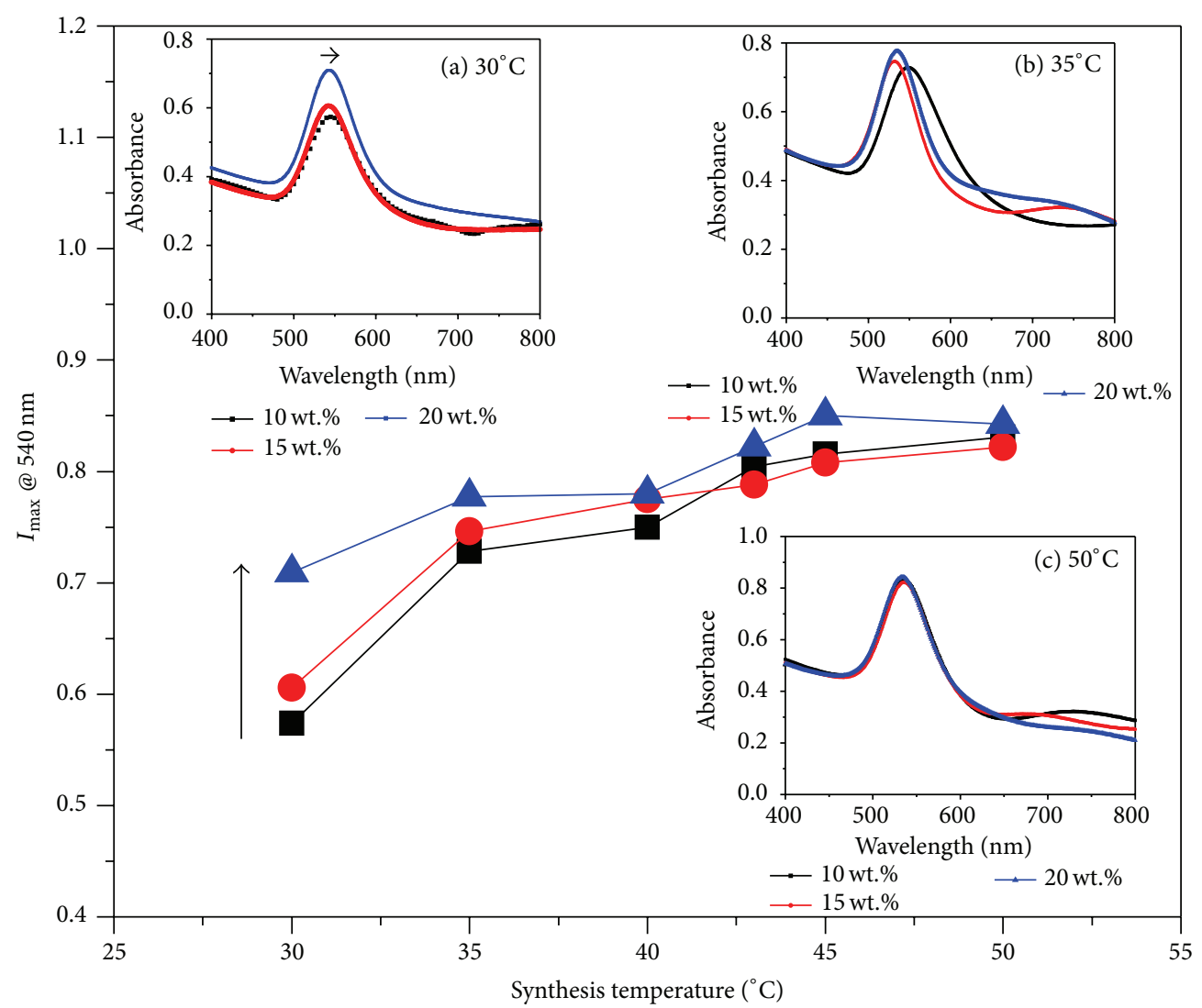

FIGURE 3: Intensity of the UV-Vis absorbance peak measured at $540 \mathrm{~nm}$ versus synthesis temperature for $\mathrm{HAuCl}_{4}$ and $\mathrm{P}_{103}$ aqueous solutions

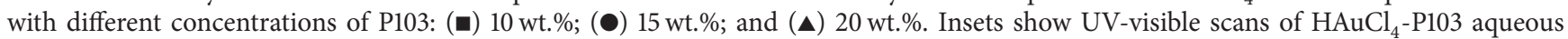
solutions.

In our study, regions below and above the CP show an increase in the intensity of absorbance. Micelles and polymer aggregates tend to merge to produce larger respective assemblies with greater surface area. That in turn enhances the reduction process and thereby increases the intensity. However, at CPT point, $I_{\max }$ remained almost constant for three concentrations due to micelles starting to get dehydrated at around $40^{\circ} \mathrm{C}$ and achieved a predominantly hydrophobic environment [2]. The nondependence of $I_{\max }$ with polymer concentration suggests that the nucleating centers remain constant. To study the effect of CPT on Au-NPs formation, absorbance was plotted against wavelength at $50^{\circ} \mathrm{C}$ (inset (c) in Figure 3). In this UV-Vis spectrum, it was possible to observe sharp peaks with maximum absorbance at ca. $540 \mathrm{~nm}$. This behavior suggested that polymer aggregates facilitated the reduction reaction from $\mathrm{Au}$ (3) to $\mathrm{Au}(0)$. Other absorption bands were observed at ca. $725 \mathrm{~nm}$. The presence of these bands was due to self-aggregation of independent large Au-NPs [25]. Interestingly, there is a dependence between temperature and the band associated to the selfaggregation of the NPs. Notice that at $50^{\circ} \mathrm{C}$ (above the CPT), the band shifts to lower wavelength values compared to the band at temperature at $35^{\circ} \mathrm{C}$ (below the CPT). This correlation is related to the shape of the micellar assemblies. Electron transmission microscope (TEM) observations helped us to understand the morphology of Au-NPs and micellar assemblies below and above the CPT.

TEM studies of the synthesized samples at $30^{\circ} \mathrm{C}$ demonstrated how the relationship between micelles and Au-NPs resulted in a soft template where small Au-NPs were arranged on the surface of micelles (hybrid gold/P103 nanomaterials). This effect is illustrated in Figure 4, where well defined spherical micelles carried Au-NPs of different length on their surfaces (hybrid gold nanomaterials). No independent AuNPs were observed suggesting that $\mathrm{Au}-\mathrm{NPs}$ grew on the surface cavities and used micelle surface as template to selfassemble. Au-NPs grew in size and became more prominent when a larger amount of P103 was used.

Figure 4(a) shows the results obtained where $10 \mathrm{wt} . \%$ of P103 was employed. Micelles formation loaded with tiny $\mathrm{Au}-\mathrm{NPs}$ (TNPs) of 1-2 nm was observed (see Figure 4(g)). When P103 concentration augmented to $15 \mathrm{wt} . \%$, micelles and nanoparticles increased in size, since spherical micelles with average diameters of $70 \mathrm{~nm}$ and TNPs of $4 \mathrm{~nm}$ were observed (Figures 4(b), 4(c), and 4(h)). For P103 at 20 wt.\%, micelles grew again (ca. $120 \mathrm{~nm}$ ) as well as TNPs reaching sizes up to $6 \mathrm{~nm}$ (Figures 4(d), 4(e), 4(f), and 4(i)). The magnified view of a single micellar aggregate showed that the surface was fully covered by TNPs (Figures 4(e) and 4(f)). TNPs synthesized in this way were often close to be monodisperse, 


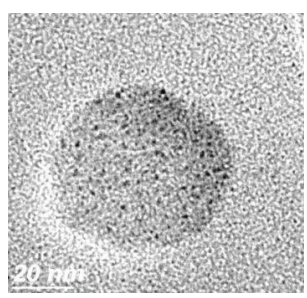

(a)

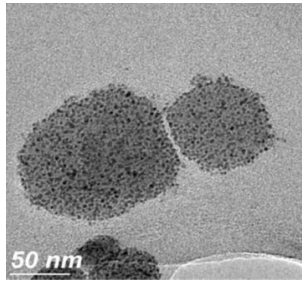

(d)

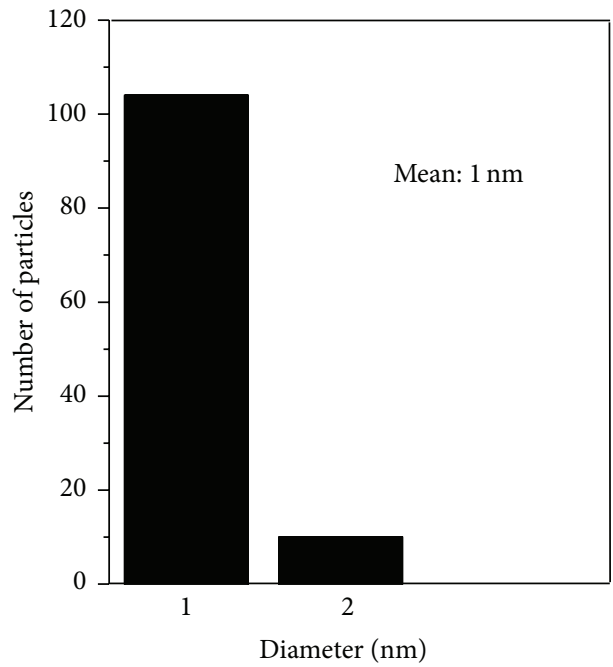

(g)

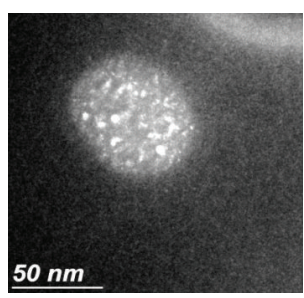

(b)

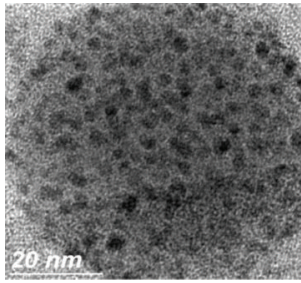

(e)

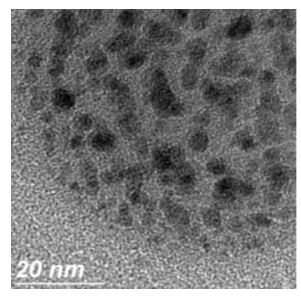

(c)

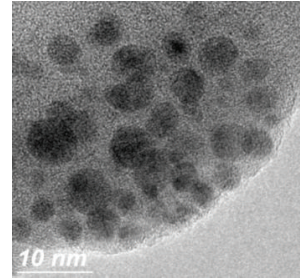

(f)

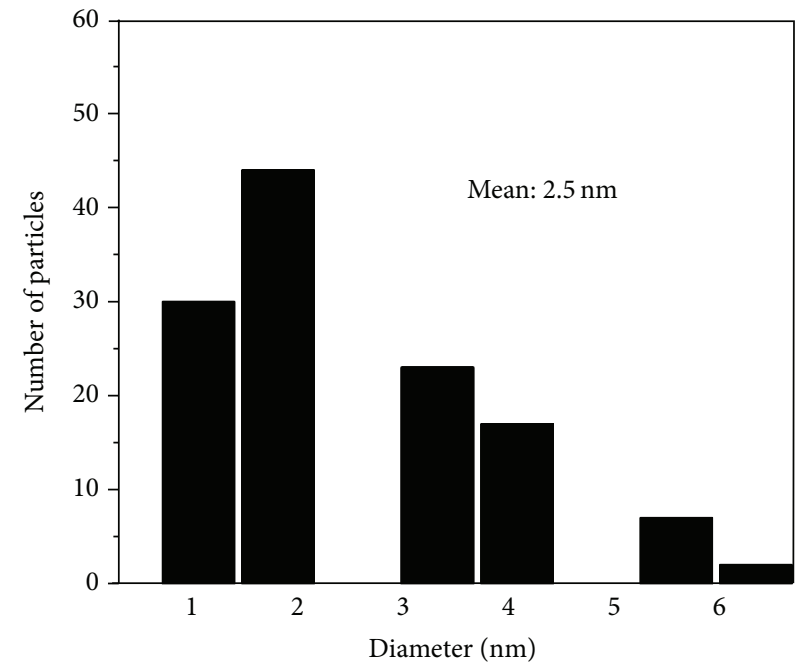

(h)

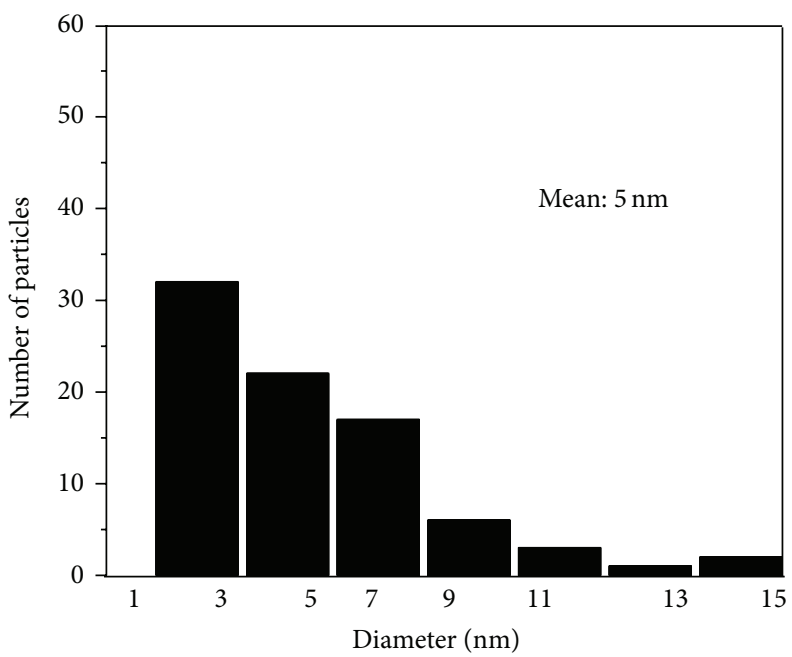

(i)

Figure 4: Transmission electron micrographs of $\mathrm{HAuCl}_{4}$ and $\mathrm{P} 103$ aqueous solutions at different P103 concentrations: (a) 10 wt.\%, (b, c) $15 \mathrm{wt} . \%$, where image were taken in dark field mode, and (d, e, f) $20 \mathrm{wt} . \%$ prepared at $30^{\circ} \mathrm{C}$. (g)-(i) Particle size distribution of Au-NPs at different P103 concentrations: (g) 10 wt.\%, (h) 15 wt.\%, and (i) 20 wt.\%. 
because their growth was mainly controlled by the number of the produced nucleating centers $[2,26]$. This feature makes them interesting for their possible role as catalysts [27] and for medical applications such as chemotherapy and diagnosis of cancer cells [28].

Most of the published work related to the self-assembled behavior of block copolymer micelles and Au-NPs is restricted to spherical or vesicular morphologies where mostly a uniform distribution of Au-NPs is observed, mainly attributed to electrostatic interactions on the micelle-solution interface. However, for many applications, it is equally important to introduce the Au-NPs in the core of the polymer-like micelles $[29,30]$ in order to obtain Au-NPs with different shapes. Under the same reaction conditions but at $35^{\circ} \mathrm{C}$, no spherical micelles assemblies were observed (Figures 5(a) and 5(b)). Instead, polymer-like micelles were observed. For 10 wt.\% of P103, TNPs covered the entire polymer-like micellar surface providing a dark contrast; however, some independent spherical Au-NPs with an average size of $9 \mathrm{~nm}$ were identified. These results can be attributed to the copolymer polydispersity, since it is known that they have a broad polydispersity distribution. When the same reaction was carried out at $15 \mathrm{wt} . \%$ of P103 (Figures 5(c) and 5(d)), large Au-NPs were observed (ca. $34 \mathrm{~nm}$ ). For samples prepared with 20 wt.\% of P103, some of Au-NPs presented shapes and sizes similar to P103 micelles (Figures 5(e) and 5(f)).

Above ca. $40^{\circ} \mathrm{C}, \mathrm{CPT}$ is reached, therefore, for samples prepared at $50^{\circ} \mathrm{C}$ (over CPT) and $10 \mathrm{wt} . \%$ of P103 (Figures 6(a) and 6(b)); long strands (indicated with white arrows) were observed rather than polymer-like micelles; above CPT long strands were dehydrated and were mainly composed of polymer. The arrangement of these strands allowed the formation of semispherical Au-NPs with an average size of ca. $43 \mathrm{~nm}$ and anisotropic particles. However, an increase in the amount of P103 (15 wt.\%) produced a great variety of morphologies; that is, spherical nanoparticles had a size of ca. $60 \mathrm{~nm}$, while nanorods were ca. $270 \mathrm{~nm}$ (Figures 6(c) and 6(d)). By adding a larger amount of polymer the occurrence of polymer-polymer contacts was promoted allowing the polymer's agglomeration (Figure 6(c), indicated by one white arrow), where these templates acted as nanoreactors producing different nanostructures. With the increase in P103 concentration (20 wt.\%), polymer aggregates were larger allowing the formation of nanoparticles of the same build (Figures 6(e) and 6(f)).

Figure 7 shows zero-shear-rate viscosity as a function of rheological measurement temperature (RMT) of aqueous solution of P103 used as reference (20 wt.\%) and solutions of hybrid gold/P103 nanomaterials synthesized at $30^{\circ} \mathrm{C}$. Under these conditions, soft templates with TNPs on their surface were observed by TEM analysis (see Figure 4).

Hybrid solutions exhibited a Newtonian behavior under steady shear rate measurements from the range of $30^{\circ} \mathrm{C}$ to $40^{\circ} \mathrm{C}$ (see insets (a) and (b)), except to the gold/P103 solution at $20 \mathrm{wt} . \%$, where a shear thinning behavior was detected at shear rates larger than $10 \mathrm{~s}^{-1}$ (inset (b)). Shear thinning behavior in colloidal solutions is due to an alignment with the stream lines flow, so the Au-NPs aggregates break up and the random polymer coils orientate to the direction of flow. Figure 7 shows that aqueous solution of P103 at $20 \mathrm{wt} . \%$ (reference solution) was more viscous than hybrid solutions. Hybrid nanomaterials viscosity decreased due to presence of nanoparticles which reduced the interaction between micelles. Rheology of hybrid gold/P103 nanomaterials depends greatly on the hydrodynamics forces that act on the surface of the aggregates. Fernández and coworkers depicted the zero-shear-rate viscosity as a function of temperature for $20 \mathrm{wt} . \%$ P103 solution; they reported that an increase in RMT increases the viscosity due to a micellar growth [21]. Here, viscosity of hybrid nanomaterials increased when the RMT augmented similarity to the reference solution. Notice that viscosity between $30^{\circ} \mathrm{C}$ and $34^{\circ} \mathrm{C}$ was practically constant for three hybrid materials. This behavior is also attributed to the presence of nanoparticles; at this temperatures they inhibited partially the interaction between spherical micelles, causing the viscosity to remain constant. On the other hand, when temperature increased from $34^{\circ} \mathrm{C}$ to $40^{\circ} \mathrm{C}$, an increase in viscosity was observed due to the increase of the entanglement number density. The rheological properties of the P103 reference solution and hybrid nanomaterial solutions were highly dependent on temperature since the viscosity increased nearly two orders of magnitude. These changes are related to the spherical-to-polymer-like micellar transition, where the length of the micelles and the entanglement number density augment with increasing temperature [9]. Moreover, for the hybrid nanomaterials, it was clear that viscosity decreased when polymer concentration diminished; this fact allowed to infer that the viscosity was strongly influenced by the amount of the unreacted copolymer (residual P103).

As previously shown, the synthesis temperature modified shape and size of nanostructures. These structures affected viscosity of the hybrid gold/P103 nanomaterials. Figure 8 depicts variation of zero-shear-rate viscosity for hybrid solutions, prepared at $30^{\circ} \mathrm{C}, 35^{\circ} \mathrm{C}$, and $50^{\circ} \mathrm{C}$, versus RMT. The concentration of P103 remained constant at $15 \mathrm{wt} . \%$. When RMT was $30^{\circ} \mathrm{C}$, the viscosity was the same in all three cases. However, when the RMT increased to $34^{\circ} \mathrm{C}$, the sample synthesized at $50^{\circ} \mathrm{C}$ showed a slight increase in viscosity, possibly by presence of polymer aggregates and nanoparticles of different shapes and big sizes (see inset in Figure 8). Abdelhalim and coworkers have reported a similar behavior, where their findings revealed that Au-NPs with larger particle sizes $(50 \mathrm{~nm})$ exhibited more viscosity than those with smaller particle sizes (10 and $20 \mathrm{~nm}$ ) [20].

The same trend was observed at $37^{\circ} \mathrm{C}$ and $40^{\circ} \mathrm{C}$. When temperature of P103 was increased, micelles grew progressively and they could interact with the gold nanoparticles forming clusters that reduced its flow, leading to an increase in viscosity.

On the other hand, the hybrid gold/P103 nanomaterials prepared at $30^{\circ} \mathrm{C}$ exhibited higher viscosity than those prepared at $35^{\circ} \mathrm{C}$ (Figure 8). This behavior was attributed to the fact that at $30^{\circ} \mathrm{C}$ the hydrophilic ends (superficial cavities) of polymeric templates are exposed to the surrounding medium; thus, increasing shear rate and temperature; these cavities interact with each other increasing the size of the micelles (see white arrow in inset of Figure 8 ). At the synthesis temperature 


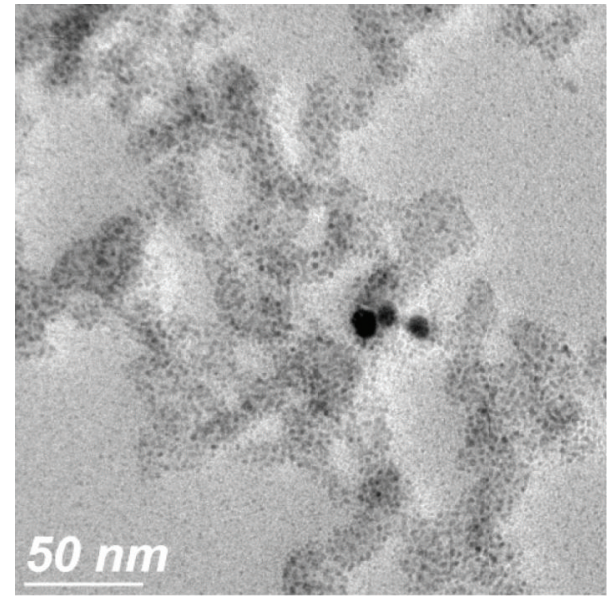

(a)

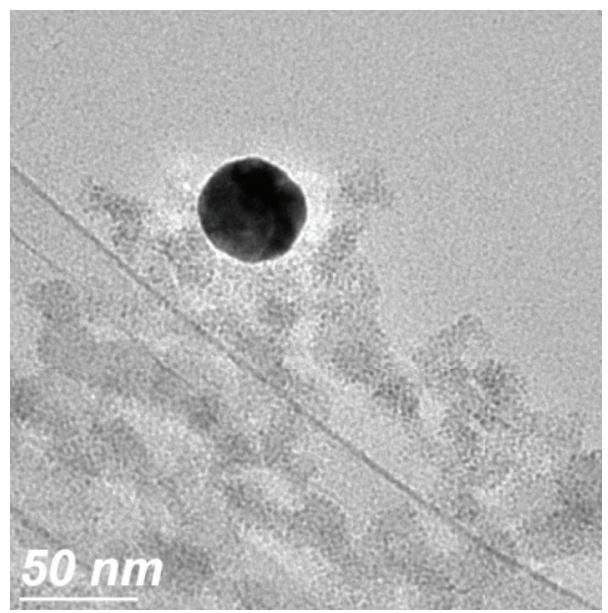

(c)

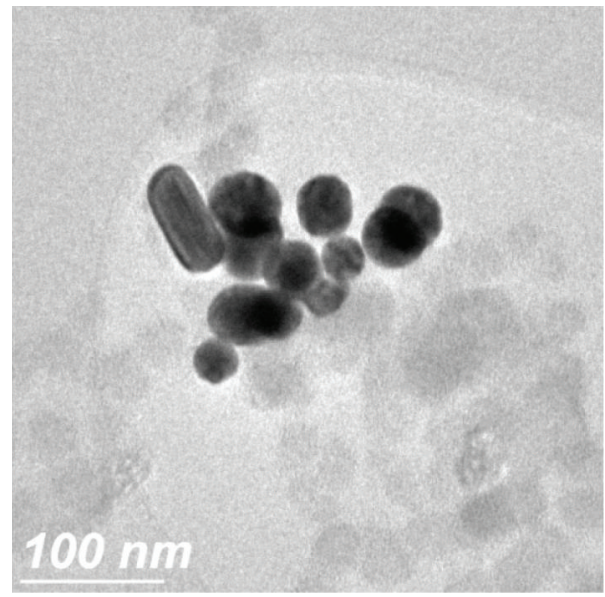

(e)

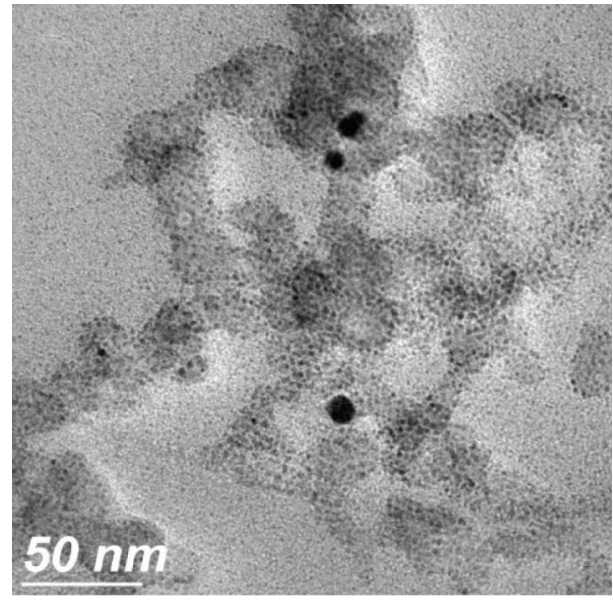

(b)

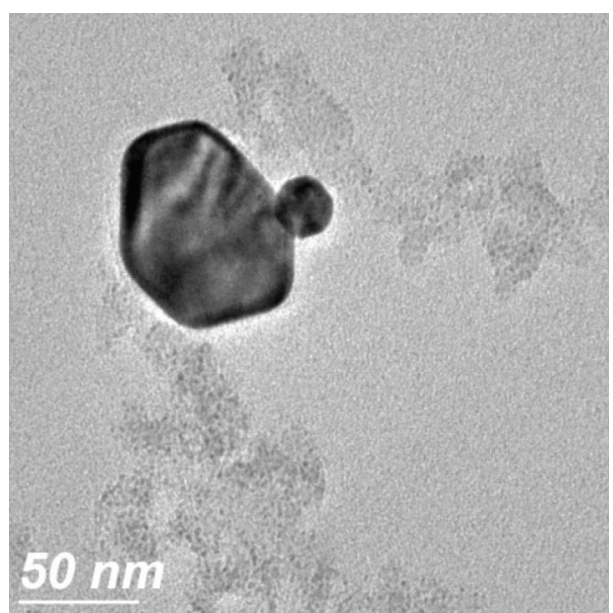

(d)

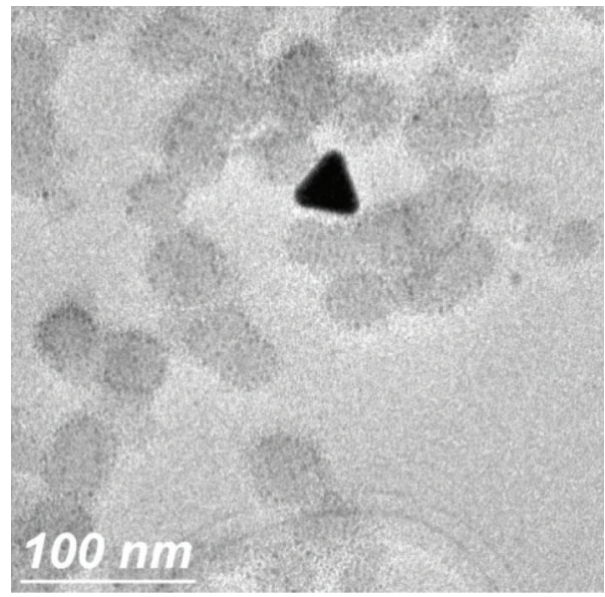

(f)

FIgURE 5: Transmission electron micrographs of $\mathrm{P} 103$ polymer like micelles loaded with small gold nanoparticles synthesized from $\mathrm{HAuCl}_{4}$ and P103 aqueous solutions prepared at different P103 concentrations and synthesis temperature of $35^{\circ} \mathrm{C}:(\mathrm{a}, \mathrm{b}) 10 \mathrm{wt} . \%$, (c, d) $15 \mathrm{wt} . \%$, and (e, f) $20 \mathrm{wt} . \%$. 


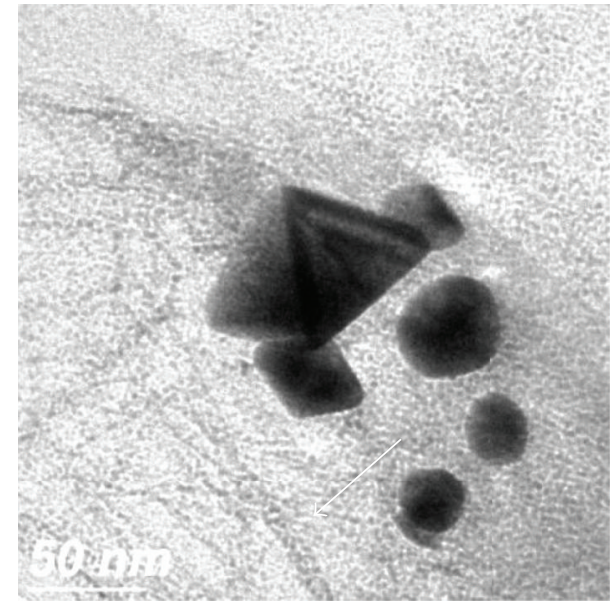

(a)

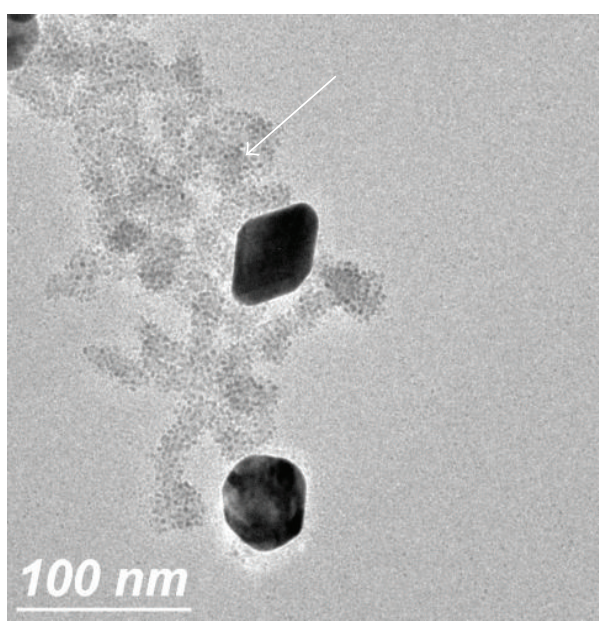

(c)

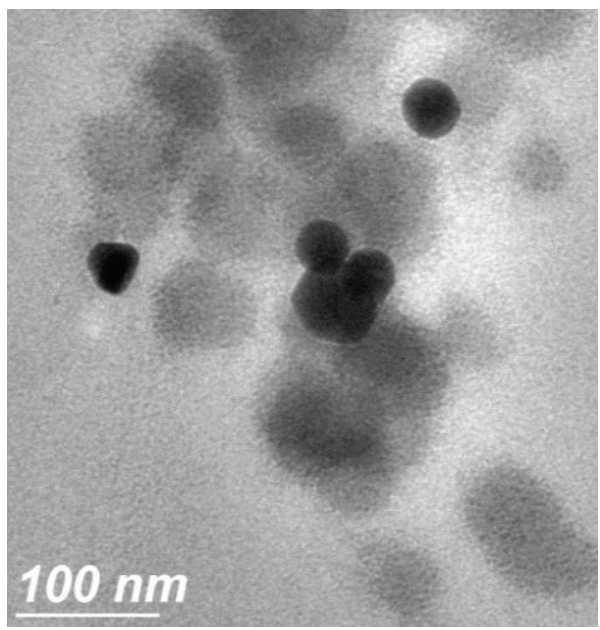

(e)

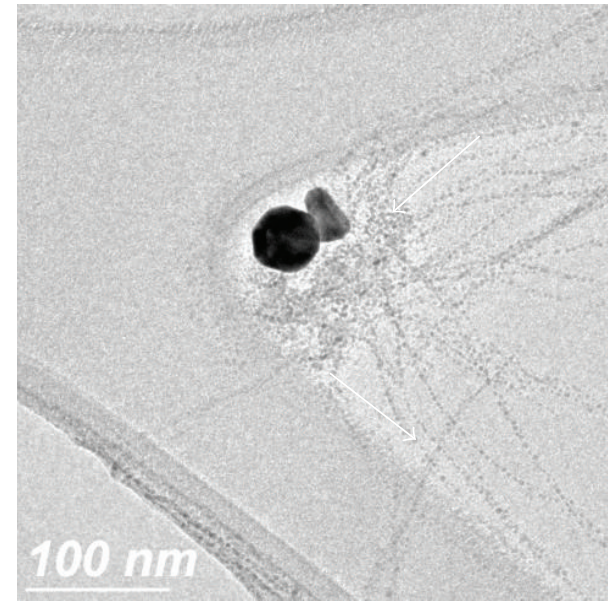

(b)

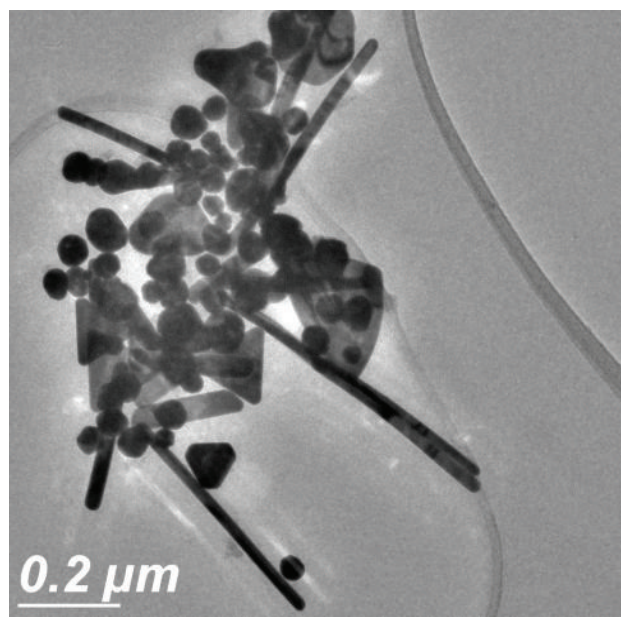

(d)

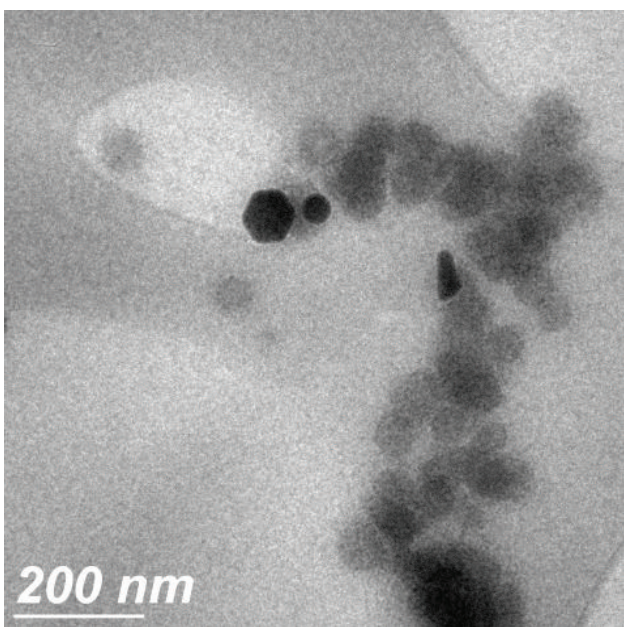

(f)

FIGURE 6: Transmission electron micrographs of $\mathrm{P} 103$ polymer like micelles loaded with small gold nanoparticles synthesized from $\mathrm{HAuCl}_{4}$ and P103 aqueous solutions prepared at different P103 concentrations and synthesis temperature of $50^{\circ} \mathrm{C}:(\mathrm{a}, \mathrm{b}) 10 \mathrm{wt} . \%$. The white arrows indicate the presence of long strands; (c, d) 15 wt.\%. The white arrow shows polymer's agglomeration; (e, f) 20 wt.\%. 


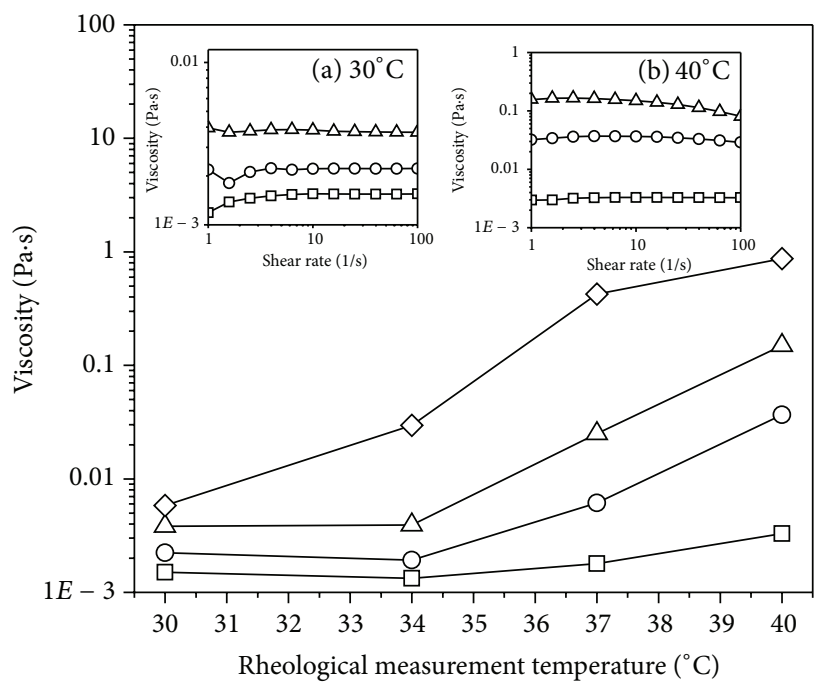

FIGURE 7: Zero-shear-rate viscosity versus rheological measurement temperature of aqueous solution of 20 wt. $\%$ of P103 as reference ( $\diamond)$ and solutions of hybrid nanomaterials with $(\Delta) 20$ wt.\% of P103, $(\bigcirc) 15 \mathrm{wt} . \%$ of P103, and $(\square) 10 \mathrm{wt} . \%$ of P103. All synthesized at $30^{\circ} \mathrm{C}$. Insets: viscosity versus shear rate for the hybrid nanomaterials at the rheological measurement temperature of $30^{\circ} \mathrm{C}$ and $40^{\circ} \mathrm{C}$. The line is a guide for the eye.
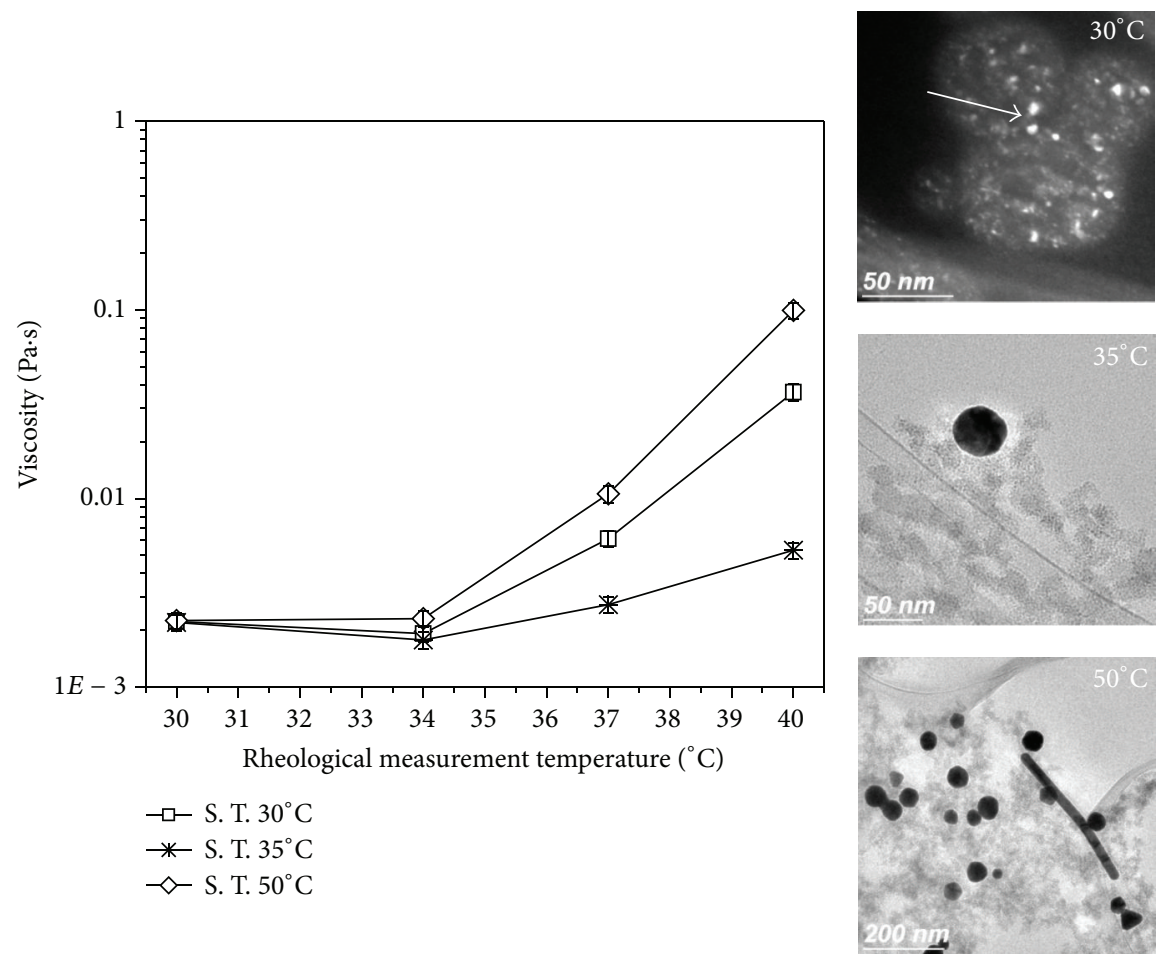

FIGURE 8: Variation of viscosity for hybrid gold/P103 nanomaterials versus rheological measurement temperature. The synthesis temperatures for these materials are $(\square) 30^{\circ} \mathrm{C}$. White arrow indicates intermicelle collisions, the image was taken in dark field mode $(*) 35^{\circ} \mathrm{C}$ and $(\diamond) 50^{\circ} \mathrm{C}$, and P103 remained constant at $15 \mathrm{wt} . \%$. The line is a guide for the eye. Right: TEM images of nanomaterials.

of $35^{\circ} \mathrm{C}$, well defined nanoparticles were formed, which was a consequence of the polymer-like micelles. If temperature increases, the micelles form is modified (which gradually dehydrates); thus the hydrophilic interactions between aggregates decrease and consequently the clusters fall apart, which causes a viscosity decrease.

\section{Conclusions}

The synthesis of gold nanoparticles (Au-NPs) using the Pluronic P103 as a reductant and soft template to design tuned hybrid gold/P103 nanomaterials was reported here. With the use of the triblock copolymer commercially known as 
Pluronic P103, it was possible to prepare tuned morphologies of gold hybrid nanomaterials. The amphiphilic character of the P103 allowed the formation of gold hybrid nanomaterials with different shapes and sizes. The results concluded that the final morphology of hybrid gold/P103 nanomaterials was entirely controlled by the form of micellar assemblies (i.e., spherical micelles, polymer-like micelles, and polymer aggregates), depending on whether they were below or above the cloud point temperature (CPT). Below the CPT, micelles underwent changes related to spherical-to-polymerlike micelles transition, where small Au-NPs arranged on the surface of micelles (which acts as soft templates) and independent $\mathrm{Au}-\mathrm{NPs}$ were formed. On the contrary, above the CPT, polymer-like micelles were dehydrated; the arrangement of these structures allowed the formation of semispherical Au-NPs and anisotropic nanoparticles. An increase in the amount of P103 produced a great variety of morphologies, in the range of spherical, rhombic, ellipsoidal, and hexagonal.

Finally, rheological measurements of aqueous solutions of hybrid gold/P103 nanomaterials showed that viscosity was sensitive to the concentration of P103 and measured temperature. Viscosity decreased when polymer concentration diminished; however, increasing measured temperature resulted in an increase in viscosity by nearly two orders of magnitude. These changes were related to a sphericalto-polymer-like micellar transition. Moreover, the synthesis temperature modified the shape and size of the nanostructures. These structures affected the viscosity, where it was observed that viscosity increased due to the presence of nanoparticles of different shapes and sizes.

\section{Conflict of Interests}

The authors declare that there is no conflict of interests regarding the publication of this paper.

\section{Acknowledgments}

The authors are very grateful to Francisco Ruiz and Jaime Mendoza for technical support at TEM measurement at UNAM. This research was financially supported by Secretaria de Educación Pública (SEP), PROMEP/103.5/10/4104 México, and Benemérita Universidad Autónoma de Puebla, VIEP 2014.

\section{References}

[1] X. Hu and S. Liu, "Recent advances towards the fabrication and biomedical applications of responsive polymeric assemblies and nanoparticle hybrid superstructures," Dalton Transactions, vol. 44, no. 9, pp. 3904-3922, 2015.

[2] P. Khullar, A. Mahal, V. Singh, T. S. Banipal, G. Kaur, and M. S. Bakshi, "How PEO-PPO-PEO triblock polymer micelles control the synthesis of gold nanoparticles: temperature and hydrophobic effects," Langmuir, vol. 26, no. 13, pp. 11363-11371, 2010.

[3] T. Sakai and P. Alexandridis, "Single-step synthesis and stabilization of metal nanoparticles in aqueous pluronic block copolymer solutions at ambient temperature," Langmuir, vol. 20, no. 20, pp. 8426-8430, 2004.

[4] R. K. Prud'homme, G. Wu, and D. K. Schneider, "Structure and rheology studies of poly(oxyethylene-oxypropyleneoxyethylene) aqueous solution," Langmuir, vol. 12, no. 20, pp. 4651-4659, 1996.

[5] P. Alexandridis, J. F. Holzwarth, and T. A. Hatton, "Micellization of poly(ethylene oxide)-poly(propylene oxide)-poly(ethylene oxide) triblock copolymers in aqueous solutions: thermodynamics of copolymer association," Macromolecules, vol. 27, no. 9, pp. 2414-2425, 1994.

[6] M. S. Bakshi and S. J. Sachar, "Influence of temperature on the mixed micelles of Pluronic F127 and P103 with dimethylene-bis(dodecyldimethylammonium bromide)," Journal of Colloid and Interface Science, vol. 296, no. 1, pp. 309-315, 2006.

[7] M. S. Bakshi and P. J. Bhandari, "Fluorescence studies on the non-ideal mixing in triblock copolymer binary mixtures under the effect of temperature: a block hydration effect," Journal of Photochemistry and Photobiology A: Chemistry, vol. 186, no. 23, pp. 166-172, 2007.

[8] R. Cardoso da Silva and W. Loh, "Effect of additives on the cloud points of aqueous solutions of ethylene oxide-propylene oxide-ethylene oxide block copolymers," Journal of Colloid and Interface Science, vol. 202, no. 2, pp. 385-390, 1998.

[9] J. G. Álvarez-Ramírez, V. V. A. Fernández, E. R. Macías et al., "Phase behavior of the Pluronic P103/water system in the dilute and semi-dilute regimes," Journal of Colloid and Interface Science, vol. 333, no. 2, pp. 655-662, 2009.

[10] Y.-L. Su, J. Wang, and H.-Z. Liu, "FTIR spectroscopic study on effects of temperature and polymer composition on the structural properties of PEO-PPO-PEO block copolymer micelles," Langmuir, vol. 18, no. 14, pp. 5370-5374, 2002.

[11] M. Aizawa and J. M. Buriak, "Nanoscale patterning of two metals on silicon surfaces using an $\mathrm{ABC}$ triblock copolymer template," Journal of the American Chemical Society, vol. 128, no. 17, pp. 5877-5886, 2006.

[12] P. Khullar, V. Singh, A. Mahal et al., “Tuning the shape and size of gold nanoparticles with triblock polymer micelle structure transitions and environments," Journal of Physical Chemistry C, vol. 115, no. 21, pp. 10442-10454, 2011.

[13] A. Slistan-Grijalva, R. Herrera-Urbina, J. F. Rivas-Silva, M. Ávalos-Borja, F. F. Castillón-Barraza, and A. Posada-Amarillas, "Classical theoretical characterization of the surface plasmon absorption band for silver spherical nanoparticles suspended in water and ethylene glycol," Physica E: Low-Dimensional Systems and Nanostructures, vol. 27, no. 1-2, pp. 104-112, 2005.

[14] K. K. Sandhu, C. M. McIntosh, J. M. Simard, S. W. Smith, and V. M. Rotello, "Gold nanoparticle-mediated transfection of mammalian cells," Bioconjugate Chemistry, vol. 13, no. 1, pp. 3-6, 2002.

[15] S. Tokonami, H. Shiigi, and T. Nagaoka, "Preparation of nanogapped gold nanoparticle array for DNA detection," Electroanalysis, vol. 20, no. 4, pp. 355-360, 2008.

[16] X. Huang, P. K. Jain, I. H. El-Sayed, and M. A. El-Sayed, "Gold nanoparticles: interesting optical properties and recent applications in cancer diagnostics and therapy," Nanomedicine, vol. 2, no. 5, pp. 681-693, 2007.

[17] Y. Ge and B. Kang, "Surface plasmon resonance scattering and absorption of biofunctionalized gold nanoparticles for targeted cancer imaging and laser therapy," Science China Technological Sciences, vol. 54, no. 9, pp. 2358-2362, 2011. 
[18] A. S. Thakor, J. Jokerst, C. Zavaleta, T. F. Massoud, and S. S. Gambhir, "Gold nanoparticles: a revival in precious metal administration to patients," Nano Letters, vol. 11, no. 10, pp. 4029-4036, 2011.

[19] Z. Krpetic, F. Porta, and G. Scarì, "Selective entrance of gold nanoparticles into cancer cells," Gold Bulletin, vol. 39, no. 2, pp. 66-68, 2006.

[20] M. A. K. Abdelhalim, M. M. Mady, and M. M. Ghannam, "Rheological and dielectric properties of different gold nanoparticle sizes," Lipids in Health and Disease, vol. 10, article 208, 2011.

[21] V. V. A. Fernández, N. Tepale, J. G. Álvarez et al., "Rheology of the Pluronic P103/water system in a semidilute regime: evidence of nonequilibrium critical behavior," Journal of Colloid and Interface Science, vol. 336, no. 2, pp. 842-849, 2009.

[22] R. G. Larson and K. E. Gubbins, The Structure and Rheology of Complex Fluids, University Press, New York, NY, USA, 1999.

[23] P. Khullar, V. Singh, A. Mahal, H. Kumar, G. Kaur, and M. S. Bakshi, "Block copolymer micelles as nanoreactors for selfassembled morphologies of gold nanoparticles," Journal of Physical Chemistry B, vol. 117, no. 10, pp. 3028-3039, 2013.

[24] B. Sepúlveda, P. C. Angelomé, L. M. Lechuga, and L. M. LizMarzán, “LSPR-based nanobiosensors," Nano Today, vol. 4, no. 3, pp. 244-251, 2009.

[25] C. J. Murphy and N. R. Jana, "Controlling the aspect ratio of inorganic nanorods and nanowires," Advanced Materials, vol. 14, no. 1, pp. 80-82, 2002.

[26] M. S. Bakshi, S. Sachar, G. Kaur et al., "Dependence of crystal growth of gold nanoparticles on the capping behavior of surfactant at ambient conditions," Crystal Growth and Design, vol. 8, no. 5, pp. 1713-1719, 2008.

[27] M. V. Seregina, L. M. Bronstein, O. A. Platonova et al., "Preparation of noble-metal colloids in block copolymer micelles and their catalytic properties in hydrogenation," Chemistry of Materials, vol. 9, no. 4, pp. 923-931, 1997.

[28] W. Cai and X. Chen, "Nanoplatforms for targeted molecular imaging in living subjects," Small, vol. 3, no. 11, pp. 1840-1854, 2007.

[29] J. Chai and J. M. Buriak, "Using cylindrical domains of block copolymers to self-assemble and align metallic nanowires," ACS Nano, vol. 2, no. 3, pp. 489-501, 2008.

[30] J.-U. Kim, S.-H. Cha, K. Shin, J. Y. Jho, and J.-C. Lee, "Preparation of gold nanowires and nanosheets in bulk block copolymer phases under mild conditions," Advanced Materials, vol. 16, no. 5, pp. 459-464, 2004. 

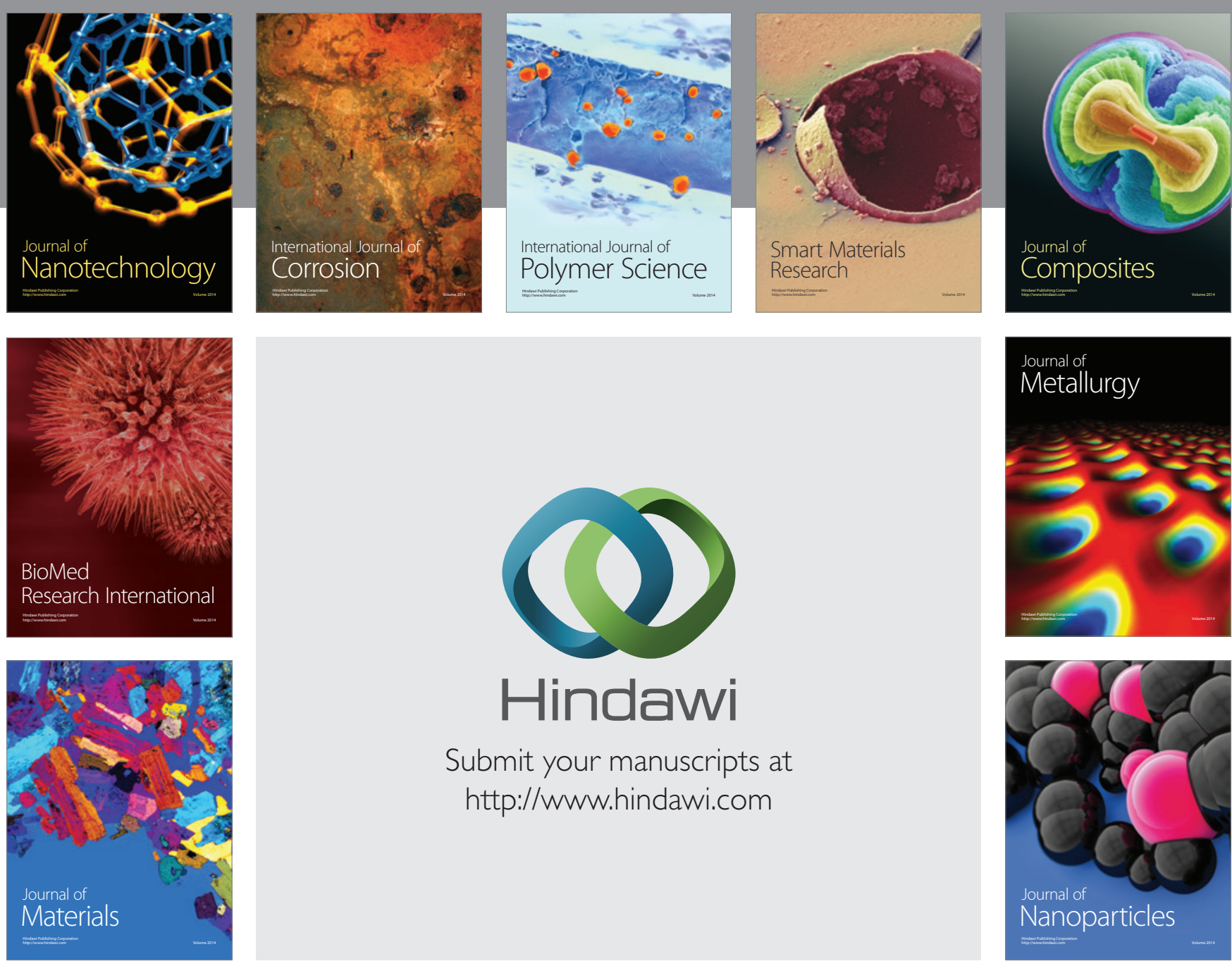

\section{Hindawi}

Submit your manuscripts at

http://www.hindawi.com

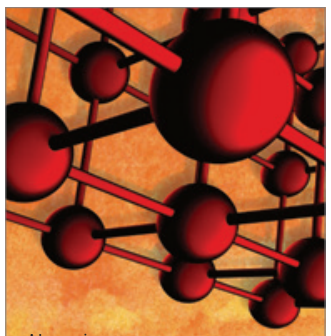

Materials Science and Engineering
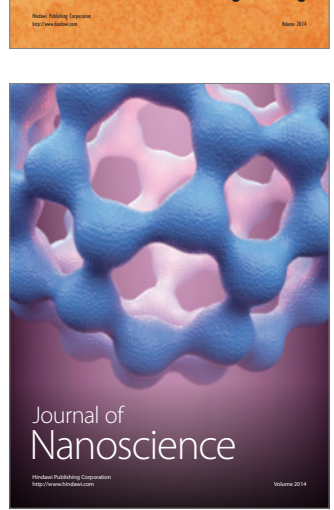
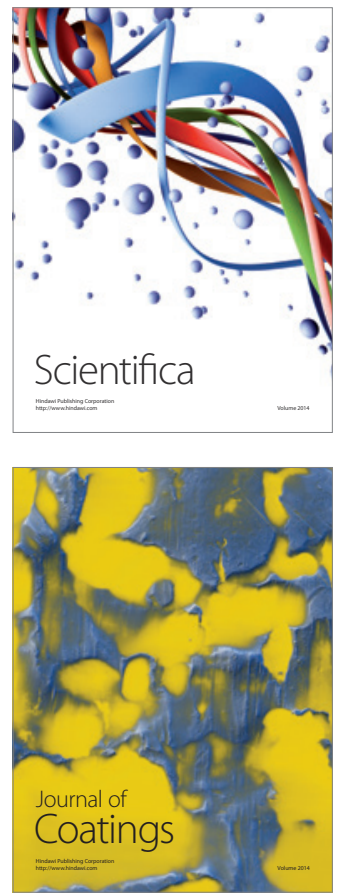
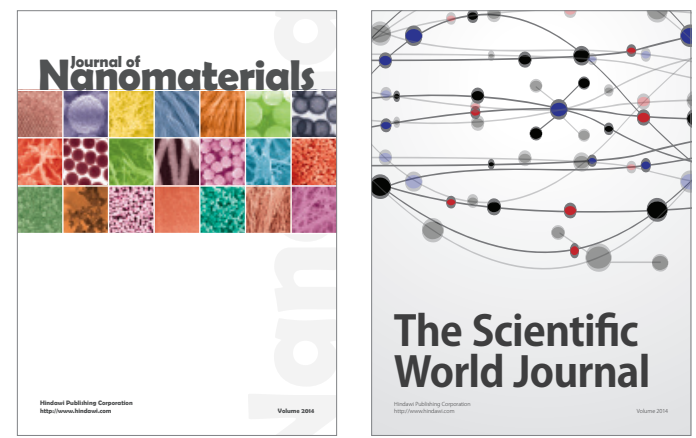

The Scientific World Journal
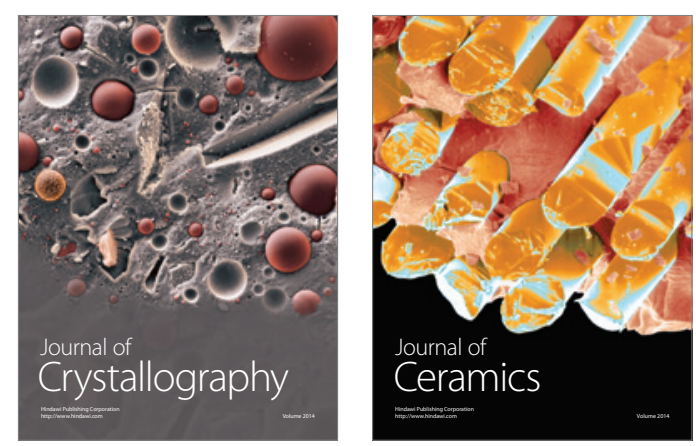
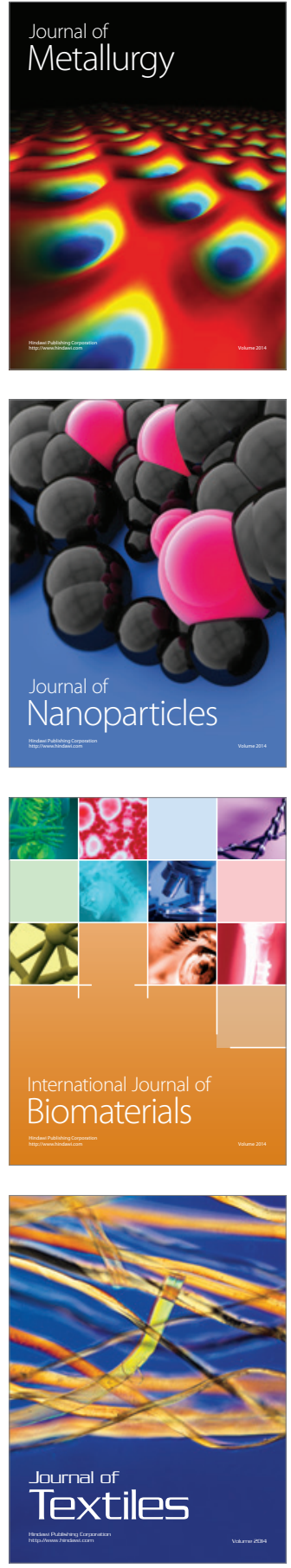